\title{
Is It Prime Time for Alpha2-Adrenocepter Agonists in the Treatment of Withdrawal Syndromes?
}

\author{
Timothy E. Albertson - James Chenoweth • \\ Jonathan Ford • Kelly Owen • Mark E. Sutter
}

Published online: 20 September 2014

(C) American College of Medical Toxicology 2014

\begin{abstract}
The need to treat withdrawal syndromes is a common occurrence in outpatient, inpatient ward, and intensive care unit (ICU) settings. A PubMed and Google Scholar search using alpha2-adrenoreceptor agonist (A2AA), specific A2AA agents, withdrawal syndrome and nicotine, and alcohol and opioid withdrawal terms was performed. A2AA agents appear to be able to modulate many of the signs and symptoms of significant withdrawal syndromes but are also capable of significant side effects, which can limit clinical use. Nonopioid oral A2AA agent use for opioid withdrawal has been well established. Pharmacologic combination therapy that utilizes A2AA agents for withdrawal syndromes appears promising but requires further formal testing to better define which other agents, under what condition(s), and at what A2AA doses are needed. The A2AA dexmedetomidine may be useful as an adjunctive agent in treating severe alcohol withdrawal syndromes in the ICU. In general, the current data does not support the routine use of A2AA as the primary or sole agent to treat ethanol/alcohol or nicotine withdrawal syndromes. Specific A2AA agents such as lofexidine has been shown to have a primary role in non-opioid-based treatment of opioid withdrawal syndrome and dexmedetomidine in combination with benzodiazepines has been shown to have potential in the treatment of severe ICU-based alcohol withdrawal syndrome.
\end{abstract}

T. E. Albertson $(\bowtie)$

Department of Internal Medicine, UC Davis, 4150 V Street, Suite 3100, Sacramento 95817, CA, USA

e-mail: tealbertson@ucdavis.edu

T. E. Albertson · J. Chenoweth · J. Ford · K. Owen · M. E. Sutter Department of Emergency Medicine, UC Davis, Sacramento, CA, USA

T. E. Albertson · J. Chenoweth $\cdot$ M. E. Sutter Department of Medicine, Veterans Administration, Northern California Health Care System, Mather, CA, USA
Keywords Clonidine $\cdot$ Alcohol withdrawal $\cdot$ Nicotine withdrawal $\cdot$ Opioid withdrawal $\cdot$ Dexmedetomidine . Tizanidine · Lofexidine · Guanfacine · Alpha2 agonists · Alpha2-adrenoceptor agonists · Withdrawal syndromes

\section{Introduction}

The use of alpha2-adrenoceptor agonists (A2AA) is extensive in human and veterinary medicine. Xylazine and the imidazole compound dexmedetomidine are both A2AA agents that have been widely used for many years to induce analgesia and sedation in animals and humans respectively [1]. Other A2AA agents are approved in the United States of America (USA) by the Food and Drug Administration (FDA) for both the treatment of hypertension and attention deficit hyperactivity disorder (clonidine an imidazole derivative and guanfacine) and for the treatment of muscle spasticity (tizanidine) [2]. The combination alpha1-adrenoceptor agonist and A2AA, oxymetazoline is approved as an over-the-counter nasal sinus decongestant spray by the FDA. The only drug approved for a withdrawal syndrome is the A2AA agent lofexidine, an imidazoline derivative, which is approved in the United Kingdom (UK) for opioid withdrawal. Figure 1 provides the chemical structures of five clinically used A2AA agents.

Adrenergic receptors were originally divided into alphaand beta-receptors based on the physiological response to various catecholamines. The stimulation of these receptors produces excitatory and inhibitory effects depending on the tissues studied [3]. Adrenergic receptors are divided into nine subtypes each encoded by separate genes with three betaadrenergic receptor subtypes [3]. The alpha-adrenoceptors have further been divided into alpha1 and alpha 2 subclasses and these also each have three different subtypes defined [1]. The alpha2-adrenoceptors (A2A) are mediated through the guanine-nucleotide regulatory binding proteins ( $\mathrm{G}$ proteins). 


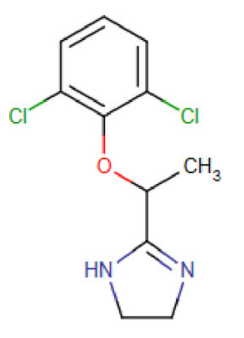

Lofexidine

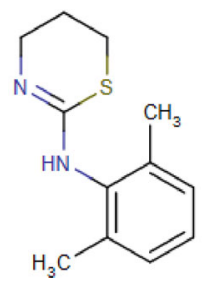

Xylazine

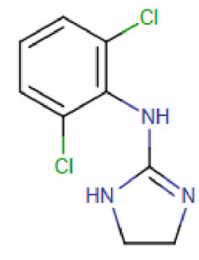

Clonidine

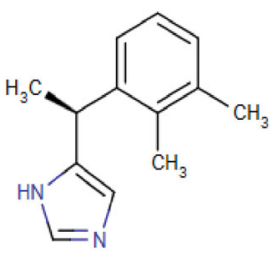

Dexmedetomidine

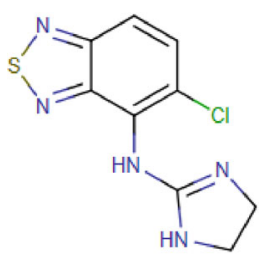

Tizanidine
Fig. 1 Chemical structures of commonly used alpha2-adrenoceptor agonists in human and veterinary medicine

Specifically, the A2A subtypes are a specific G protein (Galpha-i-coupled)-mediated receptor and have an inhibitory autoreceptor effect on noradrenergic neurons both presynaptically and postsynaptically in the brain, brain stem, spinal cord, and peripheral nervous system [3]. Many of the A2AA agents used clinically are imidazole derivatives (clonidine, dexmedetomidine, and lofexidine) and also stimulate $\mathrm{I}_{1}$ imidazoline receptors in the brain and brain stem generating a "sympathoinhibitory" therapeutic response $[4,5]$.

These complicated cellular and receptor interactions of A2AA agents result in sympatholytic properties including reduced blood pressure, bradycardia, drowsiness, sedation, fatigue, dry mouth, dry mucous membranes, hyperglycemia, and analgesia. Using a warm-water tail-withdrawal assay in rhesus monkeys, Butelman and Woods demonstrated an analgesic dose-response effect for clonidine, xylazine, and dexmedetomidine that could be reversed by the alpha2antagonist idazoxan [6]. In addition to the antinociceptive effect, these agents also demonstrated dose-dependent sedation, muscle relaxation, bradycardia, and moderate respiratory depression. Dexmedetomidine is now widely used in adults and children undergoing surgical procedures, perioperatively and postoperatively to provide sedation, anxiolytic and analgesic effects, and to reduce perioperative cardiovascular complications [7-13]. Dexmedetomidine is also approved by the FDA for up to $24 \mathrm{~h}$ of use in the intensive care unit (ICU) for sedation in mechanically ventilated patients. It has, however, been used longer than $24 \mathrm{~h}$ in the ICU for both adults and children and it is thought that its use could reduce ICU stay and time to extubation in critically ill patients [14-18]. Emerging evidence suggests that the use of dexmedetomidine may treat and prevent ICU-associated delirium [19].
Dexmedetomidine is not currently FDA approved for ICU procedures or prolonged sedation but several trials have reported its effectiveness in adults and children in both situations [20-23].

To date, the A2AA class of medication has had little diversion and human abuse linked to it. One exception is the A2AA agent xylazine used only in veterinary anesthesia for sedation and analgesia. With significant diversion, xylazine has emerged as a human drug of abuse particularly in Puerto Rico in recent years [24, 25].

In addition to the many uses of A2AA agents outlined above, this class of medications has been shown to have some efficacy in modifying withdrawal syndromes. The emerging body of literature on the use of A2AA agents as modulators and adjunctive therapy for withdrawal syndromes associated with ethanol, nicotine, and opioids exists and will be reviewed.

\section{Search Methods}

An advanced PubMed search was performed in May-June 2014. The scope of the PubMed search was English only papers between 1985 and June 2014. Keywords searched included alpha2-adrenoceptor agonists and withdrawal syndromes. In addition, specific A2AA agents and specific withdrawal syndromes (alcohol, nicotine, and opioid) were searched. The specific A2AA agents (clonidine, dexmedetomidine, tizanidine, lofexidine, and guanfacine) were searched with the term "withdrawal syndrome" and the specific withdrawal syndromes. Similar searches were done using Google Scholar. The Google Scholar search was performed in June 2014 and was English only papers and did not go beyond 1985. The references of each paper were reviewed for any additional relevant publications not found on the multiple searches. Priority was given in order to metaanalysis and systemic reviews, randomized control trials, case series, and case reports.

\section{Ethanol Withdrawal}

Ethanol or alcohol withdrawal syndrome (AWS) is a major medical problem frequently faced by physicians practicing in the outpatient, inpatient, and ICU settings [26-28]. The high frequency of this syndrome in clinical practice is related to the 7 to $16 \%$ prevalence of adult alcohol dependence and/or abuse seen in the USA [29]. A study of a general hospital in Australia found $8 \%$ of the adult patient population was at risk for AWS and an incidence of AWS of $31 \%$ was reported in trauma patients [30]. Newer approaches are warranted when current protocol-driven pharmacotherapy is not adequately controlling the withdrawal physiology. 
Benzodiazepines have become the cornerstone in the treatment of AWS in both the outpatient and inpatient settings [26-28, 31]. Other agents used primarily as adjunctive pharmacotherapies include phenobarbital, propofol, gammahydroxybutyric acid (GHB), carbamazepine, and valproic acid. The butyrophenone haloperidol, the atypical antipsychotic agents risperidone and quetiapine, and the betaadrenoceptor antagonists atenolol and propranolol have been used as adjunctive therapy to the predominant gamma-butyric acid (GABA)-mediated agents such as the benzodiazepines and phenobarbital $[26,28,31]$.

\section{Clonidine and AWS}

Several A2AA agents have been used as adjunctive agents in the treatment of AWS [26-28, 31]. With chronic alcohol use, there is a widespread alteration of central and peripheral nervous system noradrenergic signaling. In withdrawal states, there is excessive and elevated noradrenergic signaling which explains why A2AA agents are logical adjunctive agents [32]. The use of A2AA agents reduces the autonomic symptoms of AWS including tachycardia, tremor, sweating, and hypertension but have not specifically been shown to prevent delirium tremens or seizures [33].

Although previous reviews on the treatment of AWS in both inpatient and outpatient clinical settings have included A2AA as adjunctive agents, limited prospective data exists to guide the clinician in their appropriate use [28, 31, 34]. Several small studies have evaluated the use of A2AA agents in the prevention of AWS. A study of 44 alcoholics admitted without AWS were randomized to either clonidine or placebo. Nine percent of the clonidine-treated group and $50 \%$ of the placebo-treated group developed AWS during hospitalization [35]. Another study of 24 patients with a history of alcohol abuse admitted for abdominal-thoracic esophageal cancer resection evaluated the use of clonidine in AWS. Patients were treated postoperatively with either intravenous (i.v.) clonidine or nothing. A significant $(P<0.05)$ favorable increase in the nutritional marker of a calculated six-day nitrogen balance was found in the clonidine-treated patients compared to controls [36]. In a larger and more complex study of 197 cancer surgery patients with concomitant alcohol dependence were randomized in the ICU to i.v. administration of flunitrazepam/ clonidine, chlormethiazole/haloperidol, flunitrazepam/haloperidol, or ethanol [37]. No difference was seen in the length of ICU stay, organ failure scores, incidence, or severity of AWS or major complications between the four groups. Tracheobronchitis was significantly higher $(P=0.0023)$ in the chlormethiazole- and haloperidol-treated group [37]. The exact role of clonidine, if any, in the prevention of AWS in atrisk patients is unclear from these limited data.
Case reports have suggested successful treatment of AWS using A2AA agents [38, 39]. Small-randomized trials using clonidine versus chlormethiazole, chlordiazepoxide, diazepam, alprazolam, or placebo demonstrated that clonidine is as effective in reducing elevated heart rates and blood pressures associated with AWS as other agents. However, other studies found clonidine to be less effective in controlling some behavioral symptoms of withdrawal such as anxiety scores [40-45].

A study of 50 hospitalized men in moderate to severe AWS randomized the patients to receive either transdermal clonidine or chlordiazepoxide. The clonidine-treated patients had better control of heart rates and blood pressures and reported less anxiety, diarrhea, dizziness, headache, and fatigue than those treated with chlordiazepoxide. The chlordiazepoxide treated patients reported less nausea and vomiting than those treated with clonidine [42].

Clonidine has been included in several combination therapy studies in the treatment of AWS. In one study, a total of 180 patients with AWS were randomized to three treatment regimens including flunitrazepam/clonidine, chlormethiazole/ haloperidol, or flunitrazepam/haloperidol [46]. The ICU length of stay was not significantly different between the treatment groups. An increased frequency of pneumonia $(P=0.04)$ and time on mechanical ventilation $(P=0.03)$ was seen in the chlormethiazole/haloperidol group. An increase $(P=0.005)$ in cardiac complications and a $7 \%$ failure to control hallucinations was reported in the flunitrazepam/ clonidine group despite the reduced incidence of pneumonia and reduced time on mechanical ventilation [46]. A complicated protocol using lorazepam, haloperidol, and clonidine was studied in 26 consecutive postoperative head and neck cancer patients. This prospective study compared the protocol-treated patients to retrospective cohort controls [47]. Use of an AWS symptom-triggered protocol that included clonidine resulted in decreased delirium, violence, and AWS-related transfers compared to historical controls. Another prospective randomized trial of 42 patients with AWS compared GHB to flunitrazepam, but both groups received as needed clonidine and haloperidol [48]. The GHB-treated group required less clonidine but more haloperidol than did the flunitrazepam-treated group. An additional trial randomized 44 ICU patients diagnosed with AWS and compared continuous infusion of flunitrazepam for agitation, intravenous clonidine for sympathetic hyperactivity and intravenous haloperidol for "psychotic symptoms" to the same medications given as bolus therapy [49]. A formal alcohol withdrawal assessment tool was used to guide medication needs. The continuous infusion approach resulted in higher amounts of flunitrazepam, clonidine and haloperidol given and longer ICU stays (median difference 6 days) due to a higher incidence of pneumonia ( 43 versus $26 \%$ ) compared to the bolus approach [49]. These studies describe an important potential adjunctive role for clonidine in the treatment of AWS. 


\section{Dexmedetomidine and AWS}

Before dexmedetomidine was FDA approved, it was shown to alleviate AWS in a rat model of alcohol withdrawal [50]. Several case reports and case series have suggested that dexmedetomidine has promise as a potentially safe and effective adjuvant treatment for AWS in the ICU [51]. In a retrospective case series, 10 patients in the ICU with AWS received dexmedetomidine with benzodiazepines. The authors suggested the addition of dexmedetomidine was safe and blunted autonomic hyperactivity [52]. A retrospective case series of 33 critically ill adult ICU patients with AWS were given a mean dexmedetomidine dose of $0.7 \mu \mathrm{g} / \mathrm{kg} / \mathrm{h}$ (range $0.4-0.7$ ) to achieve the desired level of sedation in addition to benzodiazepines [53]. In $12 \mathrm{~h}$ after dexmedetomidine was started, the benzodiazepine requirements significantly decreased $(P<0.001)$ and both blood pressure $(P=0.03)$ and heart rate $(P<0.001)$ decreased. Hypotension was seen in four $(12 \%)$ of patients. Another series of 18 ICU patients with AWS and delirium had dexmedetomidine added to a benzodiazepinebased sedation regimen. The dexmedetomidine-treated group averaged $23.9 \mathrm{~h}$ in treatment duration with a maximum infusion dose of $1.5( \pm 1.2$ standard deviation $) \mu \mathrm{g} / \mathrm{kg} / \mathrm{h}$. Alcohol withdrawal symptom control was obtained and none of these patients required intubation. No adverse events were reported in this series and the authors considered the use of dexmedetomidine to be safe in this patient population [54]. A retrospective analysis of 17 patients treated with benzodiazepines used dexmedetomidine as an adjunctive treatment for severe AWS in the ICU found a $61.5 \%$ reduction $(P<0.001)$ in benzodiazepine dosing [55]. Significant reductions of alcohol severity scores $(P=0.015)$ were reported after starting dexmedetomidine along with less tachycardia and hypertension. One patient developed a $9 \mathrm{~s}$ systolic pause resulting in discontinuation of the drug. Fifty chronic alcoholic patients undergoing endoscopic retrograde cholangiopancreatography (ERCP) were randomized to a constant infusion of dexmedetomidine $(1 \mu \mathrm{g} / \mathrm{kg} / \mathrm{h}$ loading followed by $0.7 \mu \mathrm{g} / \mathrm{kg} / \mathrm{h}$ ) or saline placebo followed by patientcontrolled propofol/alfentanil as rescue medications [56]. There was a significant $(P<0.028$ and $P<0.008)$ reduction in propofol and alfentanil used in the dexmedetomidine group. However, successful sedation was only achieved in $76 \%$ of the patients treated with dexmedetomidine versus all of those treated with placebo $(P=0.022)$. The combination therapy of dexmedetomidine and propofol/alfentanil caused mental confusion in $25 \%$ of the patients, which limited their ability to interact with the patient-controlled delivery of propofol/ alfentanil. In addition, the dexmedetomidine-treated group had delayed recovery. Although these patients were at risk for but not in AWS, it does point to potential limitations for the use of dexmedetomidine, suggesting that its may be indicated only for a select group of severe AWS patients. In the only prospective randomized, double-blind, placebo-controlled trial, 24 adult ICU patients with AWS were randomized to dexmedetomidine $1.2 \mu \mathrm{g} / \mathrm{kg} / \mathrm{h}$ (high dose), dexmedetomidine $0.4 \mu \mathrm{g} / \mathrm{kg} / \mathrm{h}$ (low dose) or placebo as adjunctive therapy to lorazepam for up to 5 days [57]. Reduction in 24-h lorazepam requirements was seen with the addition of dexmedetomidine comparing before versus after doses to those required in the placebo group. A reduction of $56 \mathrm{mg}$ of lorazepam in the high dose dexmedetomidine treatment group and $8 \mathrm{mg}$ of lorazepam in the low dose dexmedetomidine treatment group was reported for the first $24 \mathrm{~h}(P=0.037)$. There was no statistical difference in the 7 days total lorazepam dose, and sedationagitation scale scores were similar for dexmedetomidine and placebo treatment groups. Bradycardia was more frequent with dexmedetomidine treatment, particularly in the high dose group. The investigators concluded that the use of adjunctive dexmedetomidine in AWS reduces short-term (but not longterm) benzodiazepine requirements but at the cost of the need for close cardiac monitoring because of the incidence of bradycardia [57]. These authors, and others, have stressed the need for further well-controlled, prospective trials to define the role of dexmedetomidine in the treatment of AWS $[51,57,58]$.

\section{Other A2AA Agents and AWS}

Other A2AA agents have been considered for the treatment of AWS. The imidazoline derivative, tizanidine, which is approved for muscle spasm in the USA by the FDA, has been proposed as an agent for treatment of AWS, but has not been formally tested [59]. The A2AA imidazole derivative, lofexidine, is approved in the UK for opioid withdrawal syndrome (OWS). A small open-label trial evaluated 28 patients admitted to hospitals with AWS and who were treated with lofexidine [60]. Treatment resulted in improvement in the alcohol withdrawal rating scales, heart rates, and blood pressures during the 7-day study period. A randomized controlled trial of lofexidine compared to placebo in 63 males hospitalized with AWS showed an improvement in clinical withdrawal scores in the lofexidine-treated group [61]. More placebotreated patients failed because of intolerable withdrawal symptoms than those treated with lofexidine (6 versus 1 ) and had to be treated with benzodiazepines [61]. However, in a more recent study, 72 patients admitted for alcohol detoxification were prospectively randomized to either lofexidine or placebo tablets in addition to the standard chlordiazepoxide regimen [62]. The lofexidine-treated group had worse clinical withdrawal scores $(P<0.05)$, greater problems with hypotension, more adverse effects, and no greater completion to end of trial. The authors felt that lofexidine added "no discernible benefit" as an adjunctive medication to chlordiazepoxide in the treatment of AWS [62]. 


\section{Recommendation Regarding A2AA Agents and AWS}

Although more comparative randomized outcome-based data are clearly needed, a recent review of the use of A2AA agents in the treatment of AWS has concluded that both clonidine and dexmedetomidine can play an important adjunctive role to benzodiazepines [63]. Table 1 summarizes the important clinical trials of A2AA agents and AWS. A reduction of the total dose of what is often very high dose of benzodiazepine therapy in the treatment of AWS is thought to reduce the potential for prolonged delirium and sedation seen in these patients. The high cost of the A2AA agent dexmedetomidine compared to benzodiazepines is another consideration but will likely be mediated by the drug soon becoming generic. The need for cardiac monitoring of patients treated with parenteral or high-dose oral A2AA agents will limit their use to severe AWS patients who are in monitored beds. The development of protocols to better define and standardize the exact clinical settings and dose ranges used in AWS for both clonidine and dexmedetomidine is needed and will likely require more detailed clinical research.

\section{Opioid Withdrawal}

Chronic use of high-dose opioids leads to tolerance of their effects including reduced analgesic, sedative, and respiratory depression effects [64]. Neurons in the brain stem that stimulate wakefulness, respiration, blood pressure, and general alertness are modulated by chronic opioid exposure. Many of these neurons are noradrenergic and have a high density of presynaptic mu-opioid receptors [64]. When these mu-opioid receptors are stimulated by large amounts of opioid agonists, the neurons suppress their normal release of noradrenaline leading to drowsiness, decreased respiratory drive, and lowered blood pressure, which can be dramatic in opioid overdoses. Sudden removal of the opioid-induced inhibition on these cells can result in excessive release of noradrenaline eliciting jitters, anxiety, increased respirations and blood pressure, muscle cramps, and diarrhea. Other withdrawal symptoms include increase in pain sensation, irritability, insomnia, skin piloerection, and an influenza-like syndrome characterized by rhinorrhea, lacrimation, and myalgias caused by removal of opioids from other areas of the brain [65]. This constellation of signs and symptoms with the abrupt removal of opioids in a tolerant person is the opioid withdrawal syndrome (OWS).

\section{Clonidine and OWS}

As early as the 1970s, investigators studied the A2AA agent clonidine in the treatment of OWS. A small, double-blind, placebo-controlled, cross-over trial in 11 opioid addicted patients demonstrated the elimination of the objective signs and subjective symptoms of OWS during a 240-360-min interval after clonidine [66]. A 6 days, double-blind, randomized trial of 127 patients treated with low doses of the opioid antagonist naltrexone $(0.125$ or $0.25 \mathrm{mg} /$ day $)$ and clonidine $(0.1-0.2 \mathrm{mg}$ every $6 \mathrm{~h}$ ) coupled with a methadone taper was compared to each medication individually or placebo coupled with a methadone taper demonstrated low-dose naltrexone was more effective than placebo or clonidine [67]. However, the combination of naltrexone with clonidine was the most effective treatment and was not associated with adverse events compared to the other treatments. Clonidine has been reported to reduce OWS symptoms in special populations such as neonates and cancer patients either alone or in combination with an opioid $[68,69]$. Clonidine patches were used in 10 pediatric patients undergoing laryngotracheal surgery as prophylaxis against narcotic and sedative withdrawal with good results [70]. Other trials have compared clonidine to opioid-based therapy including meperidine, buprenorphine, and the enkephalinase inhibitor acetorphan or baclofen in the treatment of OWS [71-74]. Together, these studies point to clonidine markedly reducing, but not eliminating, all the signs and symptoms of OWS. The resulting pattern of opioid withdrawal signs and symptoms is different with less sympathomimetic symptoms in patients treated with A2AA agents than those seen with opioid-based approaches [75].

\section{Lofexidine and OWS}

The use of the A2AA agent lofexidine has been studied since the early 1980s and has been advocated in the treatment of OWS [76-78]. Randomized, double-blind, placebocontrolled trials have confirmed that lofexidine is well tolerated and more efficacious than placebo [79]. Similarly, when lofexidine was compared to methadone, favorable results have been reported with the number of days to detoxification [10.2 days for lofexidine + naloxone, 6.7 days for lofexidine + placebo, and 3.9 days for methadone $(P<0.001)$ ] [80]. In a prison-based randomized, double-blind trial comparing lofexidine to decreasing doses of methadone, no statistical difference between treatment groups was seen in severity of withdrawal symptoms, blood pressure, or heart rate [81].

Several reviews have suggested that Chinese and Indian herbal medicines may play a role in the treatment of OWS [82, 83]. No differences in OWS symptoms and anxiety scores were reported when lofexidine was compared to the traditional Chinese medicine of Jinniu capsules containing herbs and marine product extracts in heroin-addicted patients [82, 84]. Several studies have compared lofexidine to clonidine in the treatment of OWS [85-87]. Two randomized, double-blind trials reported that lofexidine was equally effective as clonidine in modulating the symptoms of OWS but lofexidine had fewer hypotensive episodes [85]. In a third trial, eight healthy 
Table 1 Major clinical trials evaluating A2AA agents in AWS

\begin{tabular}{|c|c|c|c|c|}
\hline Trial & Design & $\begin{array}{l}\text { Number of } \\
\text { patients }\end{array}$ & Drugs/doses & Outcomes \\
\hline Cushman 1985 [134] & $\mathrm{R}$ & $N=63$ & Oral P vs L/0.4 mg/q $6 \mathrm{~h} \times 8$ doses & $\mathrm{L}>\mathrm{P}$ in symptom control \\
\hline Brunning $1986[60]$ & $\mathrm{OL}$ & $N=28$ & Oral L/0.4-2/4 mg/day & Control of AWS symptom \\
\hline Keany $2001[62]$ & $\mathrm{R}, \mathrm{DB}$ & $N=72$ & Oral CDP + P vs L/1.2 mg twice/day & $\begin{array}{l}\mathrm{L}>\text { symptoms and more hypotension and adverse events. } \\
\text { No advantage }\end{array}$ \\
\hline Mertes 1996 [36] & OL & $N=24$ & IV P vs C/0.3-5.8 mg/day & $\mathrm{C}>\mathrm{P}$ in nitrogen balance \\
\hline Adinoff 1994 [40] & $\mathrm{R}, \mathrm{DB}$ & $N=25$ & Oral P vs A vs DZP vs C/0.1 mg/day & C better BP but less symptom control \\
\hline Baumgartner 1987 [41] & $\mathrm{R}, \mathrm{DB}$ & $N=47$ & Oral CDP vs C/0.2-0.4 mg/day & $\mathrm{C}>\mathrm{CDP}$ in symptom control with lower BP \\
\hline Manhem 1985 [43] & $\mathrm{R}$ & $N=40$ & $\begin{array}{l}\text { Oral CBZ }+\mathrm{CMZ} \text { vs P vs } \\
\mathrm{C} / 0.003-06 \mathrm{mg} / \mathrm{q} 6 \mathrm{~h}\end{array}$ & $\mathrm{C}=\mathrm{CMZ}$ in $\mathrm{BP}, \mathrm{P}$, and symptom contro \\
\hline Spies 1995 [37] & $\mathrm{R}$ & $N=147$ & $\begin{array}{l}\text { IV CMZ }+\mathrm{H} \text { vs F }+\mathrm{H} \text { vs E vs F + } \\
\text { C/0.07-3.39 } \mu \mathrm{g} / \mathrm{kg} / \mathrm{h}\end{array}$ & $\begin{array}{l}\text { No difference in groups except }>\text { tracheobronchitis in } \\
\mathrm{F}+\mathrm{H} \text { group }(P=0.0023)\end{array}$ \\
\hline Spies 2003 [49] & $\mathrm{R}$ & $N=44$ & $\begin{array}{l}\text { IV F }+\mathrm{H}+\mathrm{C} / \text { bolus } 0.15-0.3 \mathrm{mg} \\
\text { vs infusion } 0.5-2.0 \mu \mathrm{g} / \mathrm{kg} / \mathrm{h}\end{array}$ & $\begin{array}{l}\text { Bolus decr symptoms, time on ventilator, and incidence } \\
\text { of pneumonia }\end{array}$ \\
\hline Spies 1996 [46] & $\mathrm{R}, \mathrm{DB}$ & $N=159$ & $\begin{array}{l}\text { IV } \mathrm{CMZ}+\mathrm{H} \text { vs F }+\mathrm{H} \text { vs F }+ \\
\mathrm{C} / 0.5-4.0 \mu \mathrm{g} / \mathrm{kg} / \mathrm{h}\end{array}$ & $\begin{array}{l}\mathrm{F}+\mathrm{C} \text { decr time on ventilator and incidence of pneumonic } \\
\text { but higher cardiac complications }\end{array}$ \\
\hline Tolonen 2013 [54] & $\mathrm{OL}$ & $N=18$ & IV D/1.5 $( \pm 1.2) \mu \mathrm{g} / \mathrm{kg} / \mathrm{h}$ & $\begin{array}{l}\text { LOS ICU } 7.1( \pm 2.7) \text { days and } 3.8( \pm 1.3) \text { days to resolve } \\
\text { symptoms. No adverse events }\end{array}$ \\
\hline DeMuro 2012 [52] & OL & $N=10$ & IV LOR as needed $+\mathrm{D} / 0.2-1.2 \mu \mathrm{g} / \mathrm{kg} / \mathrm{h}$ & $\begin{array}{l}\text { 6-161 h infusion of D. NS reduction P and BP. Safe } \\
\text { with benzodiazepines }\end{array}$ \\
\hline Frazee 2014 [53] & $\mathrm{OL}$ & $N=33$ & $\begin{array}{l}\text { IV as needed benzodiazepine }+ \\
\mathrm{D} / 0.7(95 \% \mathrm{CI}, 0.4-0.7) \mu \mathrm{g} / \mathrm{kg} / \mathrm{h}\end{array}$ & $\begin{array}{l}\text { Median } 11 \mathrm{~h} \text { infusion with } 12 \% \text { hypotension and no } \\
\text { bradycardia. Significant }(P<0.001) \text { reduction in } \\
\text { benzodiazepine use before vs after D }\end{array}$ \\
\hline Rayner 2012 [55] & $\mathrm{OL}$ & $N=20$ & $\begin{array}{l}\text { IV as needed benzodiazepine }+ \\
\mathrm{D} / 0.53(95 \% \mathrm{CI}, 0.44-0.62) \mu \mathrm{g} / \mathrm{kg} / \mathrm{h}\end{array}$ & $\begin{array}{l}\text { A } 61.5 \% \text { reduction in benzodiazepine use before vs } \\
\text { after D. Improved cardiovascular profile. One } \\
\text { patient had } 2-9 \mathrm{~s} \text { asystolic pauses }\end{array}$ \\
\hline Mueller 2013 [57] & $\mathrm{R}, \mathrm{DB}$ & $N=24$ & $\begin{array}{l}\text { IV LOR + P vs LOR + D } / 0.4 \mu \mathrm{g} / \mathrm{kg} / \mathrm{h} \\
\text { vs LOR + D } / 1.2 \mu \mathrm{g} / \mathrm{kg} / \mathrm{h}\end{array}$ & $\begin{array}{l}\text { D reduced short-term LOR use but not long-term use. NS } \\
\text { increase in lower D dose. Maintained symptom control }\end{array}$ \\
\hline
\end{tabular}

Design: Retro Retrospective, $R$ randomized, $D B$ double-blind, $O L$ open label. Drug/doses: $I V$ intravenous, $h$ hour, $d$ day, $q n h$ every " $n$ " hours, $P$ placebo, $E$ ethanol, $F$ flunitrazepam, $C$ clonidine, $L$ lofexidine, $D Z P$ diazepam, $L O R$ lorazepam, $D$ dexmedetomidine, $H$ haloperidol, $C B Z$ carbamazepine, $C M Z$ Chlormethiazole, $C D P$ chlordiazepoxide, $A$ alprazolam, $C I$ confidence interval, Outcomes: $P$ pulse, $B P$ blood pressure, $L O S$ length of stay, $I C U$ intensive care unit, decr decreased, NS not significant

adult volunteers were stabilized on methadone, then randomized and pretreated with various doses of clonidine $(0.1$ and $0.2 \mathrm{mg}$ orally), lofexidine $(0.4,0.8$, and $1.6 \mathrm{mg}$ orally) or placebo. Each was then challenged with one of three doses of naloxone intramuscularly $(0,0.1$, and $0.3 \mathrm{mg})$ [87]. Both lofexidine and clonidine significantly reduced heart rate increases ( $P<0.001$ and $P=0.013$, respectively) seen after naloxone challenge. Similar reductions were seen in blood pressure after naloxone challenge after pretreatment with both lofexidine and clonidine, but neither consistently suppressed the subjective discomfort of naloxone-induced OWS [87]. These data and others have resulted in the approved use of lofexidine in the UK for OWS.

\section{Other A2AA Agents and OWS}

Other A2AA agents have also been tested in the treatment of OWS. A 12-day inpatient, randomized, controlled trial using clonidine, guanfacine, or decreasing doses of methadone in rapid detoxification of 90 heroin addicts reported a lower $(P<0.01)$ number of withdrawal signs and symptoms during days 2 to 5 in the methadone group but the A2AA agents controlled the signs and symptoms better by the end of the trial [88]. The use of the A2AA agents was associated with more hypotensive episodes than seen in the methadone group. A randomized, double-blind study evaluating clonidine or guanfacine in OWS in opioid addicts found both drugs controlled the abstinence syndrome. A higher degree $(P<0.01)$ of restlessness was seen in the clonidine-treated group than the guanfacine-treated group, but there was no difference between groups for most of the OWS parameters including heart rate and blood pressure [89].

The A2AA agent tizanidine has been shown to reduce naloxone-induced OWS manifestations in rats tolerant to morphine [90, 91]. A small outpatient trial of 26 heroindependent patients evaluated tizanidine compared to control treatment. Tizanidine treatment decreased the intensity of the 
OWS symptoms [92]. In a non-randomized trial, tizanidine was added to dextromethorphan in a combination therapy approach that was reported to improve clinical outcomes [93]. Large, randomized, controlled trials of the potential utility of tizanidine and guanfacine are needed to confirm their efficacy in the treatment of the OWS.

\section{Dexmedetomidine and OWS}

More recent literature has explored the potential utility of dexmedetomidine in the treatment of acute OWS. Mice administered with chronic dexmedetomidine did not develop hyperalgesia after its cessation [94]. Similarly, dexmedetomidine decreased the OWS and hyperalgesic effects after opioid withdrawal in morphine-tolerant rats [95]. Case reports and case series have noted a potential role for the A2AA agent dexmedetomidine in OWS in infants, pediatric, and adult patients [96-103]. In a study of 60 male patients addicted to opioids who underwent general anesthesia with propofol, half the patients were treated with dexmedetomidine during general anesthesia and during the first 6 days after recovery from anesthesia. The control group had no additional therapy during general anesthesia and was treated after recovery from anesthesia with oral lofexidine three times daily [104]. The dexmedetomidine group had lower average heart rate and blood pressure increases than did the control group during anesthesia and had lower OWS scores during the first 4 days after general anesthesia than did the lofexidine-treated control group. A case series of 11 patients hospitalized for opioid-induced hyperalgesia were treated in the ICU with dexmedetomidine infusions and underwent $50-100 \%$ reductions in scheduled opioids but had rescue opioids available [105]. Using this therapy, $64 \%$ of patients had a significant reduction in their baseline opioid doses at the time of discharge. Further randomized trials have been called for to better define the potential role of, and approaches for, the use of dexmedetomidine in the ICU use in modulating OWS [91].

A systematic review and meta-analysis of A2AA agents for the acute management of opioid withdrawal concluded that A2AA agents were more effective than placebo in treating OWS with a relative risk (RR) of 0.32 and $95 \%$ confidence intervals (CI) of 0.18 to 0.57 [106]. The use of A2AA agents was somewhat less effective in modifying OWS symptoms than the use of reducing doses of methadone. Duration of treatment was significantly longer with reducing doses of methadone compared to A2AA agents but hypotension or other adverse effects were more common with A2AA agents (RR 1.92, $95 \%$ CI 1.19-3.10) [106]. The authors did not feel that enough data exist on A2AA agents in the treatment of iatrogenic opioid abstinence syndrome in the ICU to draw conclusions. They found only case reports and small case series that limited their conclusions. In another review of 10 studies comparing A2AA agents to decreasing doses of methadone, Gowing concluded that methadone may be preferable to A2AA agents in outpatient OWS regimes where the risk of relapse is high [107]. On the inpatient side, the use of A2AA agents can help with rapid withdrawal and earlier symptom resolution than with decreasing methadone approaches. Clonidine and lofexidine were thought to be equally effective for inpatient treatment of OWS but lofexidine appears to have a lower incidence of hypotension than clonidine [107]. While admitting that only limited data exists, Honey et al. [108] concluded that preliminary evidence supports the use of transdermal clonidine and injectable dexmedetomidine in the treatment of OWS symptoms. Further studies using A2AA agents in patients undergoing OWS in the ICU were called for by these authors [108].

\section{Recommendations Regarding A2AA Agents and OWS}

Table 2 offers a summary of the major clinical trials of A2AA agents and OWS. Although more randomized placebocontrolled studies are needed, it appears that A2AA agents can mitigate the OWS in patients where the use of tapering opioid therapy is not indicated or desired. Lofexidine appears to have more efficacy data and perhaps to be safer than clonidine in inpatient and outpatient OWS treatment and detoxification. Dexmedetomidine is appealing for use of OWS in the ICU but also needs further studies to define its utility and limitations.

\section{Nicotine Withdrawal Syndrome}

Nicotine dependence is a common clinical condition seen in the outpatient and inpatient settings. As many as $70 \%$ of the estimated 45 million Americans who smoke tobacco would like to quit [109]. Nicotinic cholinergic receptors are involved in the rewards, tolerance, and withdrawal syndrome associated with nicotine use and addiction. In addition to nicotinic cholinergic receptors, GABA-mediated, dopaminergic, noradrenergic, glutamatergic, and alpha2-adrenergic receptors have been implicated in the mechanism of nicotine rewards, tolerance, dependence, and the nicotine withdrawal syndrome (NWS) [32, 109-113]. One of the major components of failure in attempting to quit cigarette smoking is the negative effect of the NWS.

Symptoms of NWS include anxiety, restlessness, depressed mood, irritability, anhedonia, and agitation [34, 109, 114]. Other symptoms reported to be seen with the NWS include anger, difficulty concentrating, impatience, insomnia, restlessness, constipation, cough, dizziness, increase in dreaming, and mouth ulcers [115]. Symptoms of NWS peak within the first week and can last for 2-4 weeks [115]. In the ICU, NWS is 
Table 2 Major clinical trials evaluating A2AA agents in OWS

\begin{tabular}{|c|c|c|c|c|}
\hline Trial & Design & $\begin{array}{l}\text { Number of } \\
\text { patients }\end{array}$ & Drugs/Doses & Outcomes \\
\hline Gold 1978 [66] & $\mathrm{R}, \mathrm{DB}$ & $N=11$ & Oral $\mathrm{P}$ vs $\mathrm{C} / 5 \mu \mathrm{g} / \mathrm{kg} \times 2$ doses & $\mathrm{C}>\mathrm{P}$ in symptom control \\
\hline Gold 1980 [135] & DB & $N=10$ & $\begin{array}{l}\text { Oral } \mathrm{P} \text { vs } \mathrm{C} / 6 \mu \mathrm{g} / \mathrm{kg} \text { day } 1 \text { then } \\
17 \mu \mathrm{g} / \mathrm{kg} / \text { day } \times 9 \text { days }\end{array}$ & $\mathrm{C}$ safe and well tolerated $\mathrm{C}>\mathrm{P}$ in symptom control \\
\hline Charney 1981 [136] & $\mathrm{R}, \mathrm{DB}$ & $N=25$ & Oral P vs C $/ 5-25 \mu \mathrm{g} / \mathrm{kg} /$ day & $\begin{array}{l}\text { Reduced BP and improved most but did not } \\
\text { control all symptoms }\end{array}$ \\
\hline Jasinski 1985 [137] & $\mathrm{R}, \mathrm{DB}$ & $N=10$ & $\begin{array}{l}\text { IV } \mathrm{P}+\text { oral } \mathrm{P}(\times 2) \text { vs IV MS } / 3 \mathrm{mg}+\text { oral } \mathrm{P}(\times 2) \\
\text { vs IV MS } / 6 \mathrm{mg} \text { vs oral } \mathrm{C} / 0.2 \mathrm{mg}+\text { oral } \mathrm{P}(\times 2) \\
\text { vs oral } \mathrm{C} / 0.4 \mathrm{mg}+\text { oral } \mathrm{P}(\times 2) \text { all } 3 \times \text { day }\end{array}$ & $\begin{array}{l}\mathrm{C} \text { more effective than MS in } \mathrm{BP} \text { and } \mathrm{P} \text { control } \\
\text { but MS more effective in symptom control }\end{array}$ \\
\hline Ziaaddini 2012 [72] & $\mathrm{R}, \mathrm{DB}$ & $N=35$ & Oral $\mathrm{BUP}+\mathrm{P}$ vs oral $\mathrm{P}+\mathrm{C} / 0.4-0.8 \mathrm{mg} /$ day $\times 5$ days & $\begin{array}{l}\text { Both treatments significantly }(P<0.001) \text { reduced } \\
\text { signs, symptoms, and opioid craving seen with } \\
\text { withdrawal without differences between groups }\end{array}$ \\
\hline Mannelli 2012 [67] & $\mathrm{R}, \mathrm{DB}$ & $N=127$ & $\begin{array}{l}\text { All subjects received M/30 mg/day } \\
\text { tapering over } 5 \text { days and oral } \\
\text { NTX/0.125- } 0.25 \mathrm{mg} / \text { day }+\mathrm{C} / 0.1-0.2 \mathrm{mg} / \mathrm{q} 6 \mathrm{~h} \\
\text { vs oral NTX/0.125-0.25 mg/day }+\mathrm{P} \text { vs oral } \\
\mathrm{C} / 0.1-0.2 \mathrm{mg} / \mathrm{q} 6 \mathrm{~h} \text { vs } \\
\text { NTX/0.12500.25 mg/day } \times 6 \text { days }\end{array}$ & $\begin{array}{l}\text { NTX more effective than P or C alone reducing } \\
\text { signs and symptoms. Combination of NTX + C } \\
\text { improved craving, signs and symptoms control. } \\
\text { No significant adverse events }\end{array}$ \\
\hline Hartman 1991 [73] & $\mathrm{R}, \mathrm{DB}$ & $N=19$ & IV A vs oral $\mathrm{C} \times 9$ days & $\begin{array}{l}\mathrm{A}>\mathrm{C} \text { in controlling objective withdrawal signs } \\
\text { but similar in subjective symptoms }\end{array}$ \\
\hline $\begin{array}{l}\text { Akhondzadeh } \\
2000[74]\end{array}$ & $\mathrm{R}, \mathrm{DB}$ & $N=62$ & Oral B vs C/maximum $0.8 \mathrm{mg} /$ day & $\begin{array}{l}\text { Physical signs controlled by } \mathrm{B}=\mathrm{C} \text { but }>\mathrm{C} \text { in } \\
\text { symptom control }\end{array}$ \\
\hline Malhotra 1997 [71] & $\mathrm{R}, \mathrm{DB}$ & $N=39$ & IM MEP vs oral C/0.3-0.6 mg/day $\times 7$ days & NS difference in control of signs or symptoms \\
\hline Deutsch 1996 [70] & $\mathrm{OL}$ & $N=10$ & $\begin{array}{l}\text { Transdermal C } / \text { mean } 5.8 \mu \mathrm{g} / \mathrm{kg} / \text { day } \\
\quad \text { (range } 4.2-8.5 \mu \mathrm{g} / \mathrm{kg} / \mathrm{day} \text { ) }\end{array}$ & $\begin{array}{l}\text { No severe signs or symptoms of withdrawal } \\
\text { with patches on. Two patches removed } \\
\text { prematurely and then withdrawal symptoms } \\
\text { seen. No adverse events. }\end{array}$ \\
\hline Bearn 1996 [138] & $\mathrm{R}, \mathrm{DB}$ & $N=86$ & Oral M vs L/0.6-2.0 mg/day $\times 7$ days & $\begin{array}{l}\text { Better symptom control with } \mathrm{M} \text { than } \mathrm{L} \text { but } \\
\text { similar effects on } \mathrm{BP}\end{array}$ \\
\hline Kahn 1997 [139] & $\mathrm{R}, \mathrm{DB}$ & $N=28$ & $\begin{array}{l}\text { Oral M + L/0.4-1.8 mg/day vs oral M + } \\
\quad \mathrm{C} / 0.2-0.9 \mathrm{mg} / \text { day } \times 14 \text { days }\end{array}$ & $\begin{array}{l}\text { Similar efficacy seen but fewer hypotensive } \\
\text { and adverse events with } \mathrm{L}\end{array}$ \\
\hline Lin 1997 [85] & $\mathrm{R}, \mathrm{DB}$ & $N=80$ & Oral C/0.3-0.6 mg/day vs L/0.8-1.6 mg/d & $\begin{array}{l}\text { Equal efficacy in controlling symptoms but } \\
\text { significantly }(P<0.005) \text { more episodes of } \\
\text { drug secondary to more hypotension with } \mathrm{C} \text { vs } \mathrm{L}\end{array}$ \\
\hline Carnwath 1998 [86] & $\mathrm{R}, \mathrm{DB}$ & $N=58$ & $\begin{array}{l}\text { Oral C/0.1-0.8 mg/day vs } \\
\mathrm{L} / 0.2-1.6 \mathrm{mg} / \text { day } \times 12 \text { days }\end{array}$ & $\begin{array}{l}\text { Both drugs were equal in efficacy but lower } \\
\text { side effects and fewer home visits } \\
\text { (both } P<0.05 \text { ) with L vs C }\end{array}$ \\
\hline Bearn 1998 [140] & OL & $N=61$ & $\begin{array}{l}\text { Oral } M \text { stabilized patients either tapered } \mathrm{M} \\
\text { over } 10 \text { days vs oral } \mathrm{L} / 0.6-2.0 \mathrm{mg} / \text { day } \times \\
10 \text { days vs oral } \mathrm{L} / 1.8-2.4 \mathrm{mg} / \text { day } \times 5 \text { days }\end{array}$ & $\begin{array}{l}\text { The high dose, short course of L was more } \\
\text { effective than the } 10 \text { day M or L course. No } \\
\text { difference in BP with either L course }\end{array}$ \\
\hline Bearn 2001 [141] & $\mathrm{OL}$ & $N=49$ & $\begin{array}{l}\text { Oral M stabilized patients then treated with } \\
\text { either oral } \mathrm{L} / 2.0-2.8 \mathrm{mg} / \text { day }+\mathrm{IM} \\
\text { naloxone } / 0.8 \mathrm{mg} / \text { day days } 3-6 \text { followed } \\
\text { by NTX } / 25-50 \mathrm{mg} / \text { day vs oral vs oral }\end{array}$ & $\begin{array}{l}\text { The } \mathrm{L}+\text { naloxone treatment and significantly } \\
(P<0.05) \text { less withdrawal severity than } \mathrm{L} \text { alone. } \\
\text { Equal completion rates and BP control }\end{array}$ \\
\hline
\end{tabular}

$\begin{array}{lll}\text { Howells } 2002[81] & \text { R, DB } & N=74 \\ \text { Walsh 2003 [87] } & \text { R, DB } & N=8\end{array}$

Beswick 2003 [142] R, DB $\quad N=89$

$\begin{aligned} & \text { McCambridge } \\ & 2007[80]\end{aligned} \quad \mathrm{R}, \mathrm{DB} \quad N=137$

by NTX/25-50 mg/day vs oral vs oral $\mathrm{L} / 1.8-2.0 \mathrm{mg} / \mathrm{d} \times 7$ days

Oral $\mathrm{M}$ vs L/0.6-2.0 mg/day $\times 10$ days

Oral M maintained patients challenged with IM naloxone $0,0.1$, and $0.3 \mathrm{mg}$ and pretreatment with $\mathrm{P}$ vs $\mathrm{L} / 0.4,0.8$, and $1.6 \mathrm{mg}$ vs $\mathrm{C} / 0.1$ and $0.2 \mathrm{mg}$

Oral $\mathrm{M}$ stabilized patients either $\mathrm{L} / 1.4-2.0 \mathrm{mg} /$ day $+\mathrm{IM} \mathrm{P} /$ day $\times 6$ days vs oral L/1.4-2.0 mg/day + IM naloxone $0.8 \mathrm{mg} /$ day $\times 6$ days

Oral M stabilized patients either tapered M over 10 days vs oral L/1.4-2.0 mg/day + IM P/day $\times 6$ days vs oral L/1.4-2.0 mg/day + IM naloxone $0.8 \mathrm{mg} /$ day $\times 6$ days
NS between $\mathrm{M}$ and $\mathrm{L}$ in symptom control or BP

Neither $\mathrm{L}$ nor $\mathrm{C}$ reduced naloxone-induced symptoms. Both reduced $\mathrm{BP}$ and $\mathrm{P}$

The addition of naloxone to $\mathrm{L}$ ameliorated withdrawal but did not accelerate the process

Longer period to restarting heroin with $\mathrm{L}+$ naloxone 
Table 2 (continued)

\begin{tabular}{lllll}
\hline Trial & $\begin{array}{c}\text { Design } \\
\text { patients }\end{array}$ & $\begin{array}{l}\text { Number of } \\
\text { Drugs/Doses }\end{array}$ & Outcomes \\
\hline Nasr 2012 [104] & OL & $N=60$ & $\begin{array}{c}\text { IV PROP }+ \text { oral L/0.6 mg/day vs IV D } \\
\text { for 4+ days } \\
\text { IV to SQ }\end{array}$ & L > symptoms than D \\
Tobias 2008 [97] & OL & $N=7$ & IV D/0.5 $\mu \mathrm{g} / \mathrm{kg} / \mathrm{h}$ & $\begin{array}{c}\mathrm{D} / 0.8-1.4 \mu \mathrm{g} / \mathrm{kg} / \mathrm{h} \mathrm{decr} \mathrm{by} 0.1 \mu \mathrm{g} / \mathrm{kg} / \mathrm{h} \\
\text { every } 12 \mathrm{~h} \text { for } 4-7 \text { days Prevented } \\
\text { withdrawal symptoms }\end{array}$ \\
Tobias 2006 [98] & OL & $N=7$ & $\begin{array}{c}2 \text { infants required incr in dose } \\
\text { D } / 0.7 \mu g / \mathrm{kg} / \mathrm{h} \text {. No adverse hemodynamic } \\
\text { or respiratory effects }\end{array}$
\end{tabular}

Design: Retro Retrospective, $R$ randomized, $D B$ double-blind, $O L$ open label. Drug/doses: $I V$ intravenous, $I M$ intramuscular, $S Q$ subcutaneous, $h$ hour, $d$ day, qnh every " $\mathrm{n}$ " hours, $\times$ times, $C I$ confidence interval, $P$ placebo, $M S$ morphine sulfate, $N T X$ naltrexone, $M$ methadone, $A$ acetorphan, $B$ baclofen, $M E P$ meperidine, $C$ clonidine, $L$ lofexidine, $D$ dexmedetomidine, $P R O P$ propofol, $B U P$ buprenorphine. Outcomes: $P$ pulse, $B P$ blood pressure, $L O$ length of sta, $I C U$ intensive care unit, decr decreased, NS not significant

often confounded by drug dependence, depression, pain, and anxiety [114]. Smokers admitted to the ICU were more likely male, had a history of alcoholism, and were more likely admitted for septic shock [114]. These same investigators reported that when smokers were matched to non-smokers in the ICU, smokers had a higher incidence of agitation (64 versus $32 \%, P=0.0005$ ) but no difference in the incidence of delirium. In addition, a higher incidence in self-removal of tubes and catheters occurred in the smokers group. Smokers required more interventions including sedative, analgesic and neuroleptic agents, and physical restraints than non-smokers [114].

\section{Clonidine and NWS}

The A2AA agent clonidine has been evaluated in smoking cessation trials, many of which also measured NWS symptoms. One of the first trials studied 15 heavy smokers, who abstained from cigarettes three different days and received clonidine, alprazolam, or placebo during the periods of cigarette abstinence. Both clonidine and alprazolam reduced anxiety, tension, irritability, and restlessness seen with NWS but only clonidine was found to reduce cigarette craving [116]. Additional trials have confirmed the reduction of NWS symptoms with clonidine treatment and improved rates of smoking cessation [117]. This positive effect of clonidine was found to be limited to women in some of the studies $[118,119]$. These positive findings can be contrasted to a study of 185 smokers randomized to either placebo or clonidine in a primary care setting. In this study, clonidine failed to show a benefit in smoking cessation [120].

In two double-blind, placebo-controlled trials that compared clonidine to placebo patches, transdermal clonidine treatment reduced NWS symptoms of craving, irritability, anxiety, restlessness, hunger, and difficulty concentrating
[121, 122]. In one study, 375 smokers were treated with either transdermal clonidine or placebo for a 4-day period of smoking abstinence. Each patient then went back on cigarettes and repeated the smoking abstinence with the opposite treatment so that each patient acted as their own control [123]. All of the NWS symptoms including cravings, irritability, anxiety, and restlessness were significantly $(P=0.001)$ reduced by the transdermal clonidine treatment compared to placebo with a five-fold decrease in craving and irritability reported [123]. Hilleman et al. [124] used transdermal clonidine and compared it to placebo in 48 chronic smokers. They found after 6 weeks that $19 \%$ of the placebo patients and $63 \%$ of the transdermal clonidine patients $(P<0.05)$ stopped smoking. A 4-week trial randomized 72 chronic smokers to either placebo or $0.1,0.2$, or $0.3 \mathrm{mg} /$ day transdermal clonidine patches [125]. Significantly, more patients were able to quit smoking at day 20 in each of the individual clonidine doses and when the clonidine groups were combined than in the placebo group (57 versus $19 \%, P=0.007)$. An inverse relationship was seen between blood clonidine concentrations and changes from baseline in heart rate, blood pressure, appetite, irritability, and anxiety [125]. When clonidine patch was added to behavior modification approaches, no additional adjunctive effect could be demonstrated in smoking cessation [126]. Combination therapy of transdermal clonidine paired with transdermal nicotine has been advocated for smoking cessation without rigorous experimental evidence [127].

Two meta-analyses have concluded that the use of clonidine has a statistically significant effect of 1.63 (95\% CI 1.22 to 2.18) versus placebo in promoting cessation of cigarette smoking and modifying the NWS [128, 129]. Clinically significant side effects of sedation and postural hypotension occurred in a dose-dependent manner in parallel to its efficacy. The authors concluded that clonidine treatment was not a "first-line" therapy in smoking cessation [129]. Although no reports of the use of other A2AA agents in the treatment of 
NWS could be found, dexmedetomidine has been suggested for use in attenuating the signs and symptoms of NWS in the ICU [34].

\section{Recommendations Regarding A2AA Agents and NWS}

Although the use of A2AA agents has been shown to be effective when compared to placebo in NWS, little data suggest that this approach is better than the FDA-approved smoking cessation products (nicotine, varenicline, and bupropion). The side effect profile of A2AA agents will probably limit their use to inpatient settings.

\section{Side Effects of A2AA Agents}

The major adverse effects of A2AA agents include bradycardia, hypotension, and sedation. Abrupt cessation of chronically dosed A2AA agents like clonidine is associated with a withdrawal syndrome. This includes insomnia, vivid dreams, headaches, nausea, tremor, restlessness, hiccups, stomach, and muscle pains in addition to a marked elevation in blood pressure and pulse [130] The newest A2AA agent dexmedetomidine is approved for use outside the operating room for short-term use in the ICU. Long-term use has been advocated with recent evidence that its hemodynamic effects did not limit its long-term use [131]. There have also been reports of acute dexmedetomidine withdrawal syndrome following prolonged use (5 to 6 days) in two patients [132]. A safety report from the FDA has pointed out that tolerance and tachyphylaxis have been reported with dexmedetomidine use beyond the FDA-approved 24-h interval. In addition, the safety report noted that prolonged use regardless of dose has been associated with withdrawal-induced nausea, vomiting, agitation, tachycardia, and hypertension $24-48 \mathrm{~h}$ after the last dose [133]. The knowledge and consideration of the side effects of A2AA agents is needed before calculating the risk/ benefit ratio of their use in the treatment of withdrawal syndrome.

\section{Conclusion}

Alpha2-adrenergic receptors and the associated neurotransmitter system appear to play an important role in modulating the signs and symptoms of AWS, OWS, and NWS. The use of A2AA agents has been shown to successfully alter alcohol, opioid, and nicotine withdrawal syndromes but the magnitude of these changes varies, and the side effect profile has not supported their use as the primary or sole agent and has limited the currently available A2AA agents to that of adjunctive therapy in most cases. Special patients, like those in the
ICU, may benefit from the use of newer A2AA agents like dexmedetomidine as adjunctive therapy in treating alcohol and opioid withdrawal states, but further research is needed to define its exact role, doses, and limitations. Rapid nonopioid-based detoxification with lofexidine, as a sole agent appears practical. Combination therapy that includes an A2AA agent in treating acute sick patients with AWS is promising but would benefit from formal trials to define best practices/protocols, doses, and drug pairings. It is too soon to say that A2AA agents have reached a "prime time" designation but they appear to be close in the approach to AWS and OWS.

Conflict of Interest Drs. Timothy E. Albertson, James Chenoweth, Jonathan Ford, Kelly Owen, and Mark E. Sutter declare no conflicts that relate to this paper.

\section{References}

1. Gertler R et al (2001) Dexmedetomidine: a novel sedative-analgesic agent. Proc (Bayl Univ Med Cent) 14(1):13-21

2. Fodd and Drug Administration. 2014. [cited June 2014]; Available from: http://www.accessdata.fda.gov/scripts/cder/drugsatfda/index. $\mathrm{cfm}$.

3. Schmidt KT, Weinshenker D (2014) Adrenaline rush: the role of adrenergic receptors in stimulant-induced behaviors. Mol Pharmacol 85(4):640-50

4. Nikolic K, Agbaba D (2012) Imidazoline antihypertensive drugs: selective i (1)-imidazoline receptors activation. Cardiovasc Ther 30(4):209-16

5. Edwards LP et al (2012) Pharmacological properties of the central antihypertensive agent, moxonidine. Cardiovasc Ther 30(4):199 208

6. Butelman ER, Woods JH (1993) Effects of clonidine, dexmedetomidine and xylazine on thermal antinociception in rhesus monkeys. J Pharmacol Exp Ther 264(2):762-9

7. Wijeysundera DN, Naik JS, Beattie WS (2003) Alpha-2 adrenergic agonists to prevent perioperative cardiovascular complications: a meta-analysis. Am J Med 114(9):742-52

8. Bhana N, Goa KL, McClellan KJ (2000) Dexmedetomidine. Drugs 59(2):263-8, discussion 269-70

9. Chabot-Dore AJ, et al. Analgesic synergy between opioid and alpha-2 adrenergic receptors. Br J Pharmacol, 2014.

10. Gerlach AT, Murphy CV, Dasta JF (2009) An updated focused review of dexmedetomidine in adults. Ann Pharmacother 43(12): 2064-74

11. Hosokawa K et al (2010) Dexmedetomidine sedation in children after cardiac surgery. Pediatr Crit Care Med 11(1):39-43

12. Goksu $\mathrm{S}$ et al (2008) Effects of dexmedetomidine infusion in patients undergoing functional endoscopic sinus surgery under local anaesthesia. Eur J Anaesthesiol 25(1):22-8

13. Wijeysundera DN, Bender JS, Beattie WS. Alpha-2 adrenergic agonists for the prevention of cardiac complications among patients undergoing surgery. Cochrane Database Syst Rev, 2009 (4): p. $\mathrm{Cd} 004126$

14. Hoy SM, Keating GM (2011) Dexmedetomidine: a review of its use for sedation in mechanically ventilated patients in an intensive care setting and for procedural sedation. Drugs 71(11):1481-501 
15. Ozaki M et al (2014) Safety and efficacy of dexmedetomidine for long-term sedation in critically ill patients. J Anesth 28(1):38-50

16. Gupta P et al (2012) Safety and efficacy of prolonged dexmedetomidine use in critically ill children with heart disease*. Pediatr Crit Care Med 13(6):660-6

17. Pasin L et al (2013) Dexmedetomidine as a sedative agent in critically ill patients: a meta-analysis of randomized controlled trials. PLoS One 8(12):e82913

18. Tan JA, Ho KM (2010) Use of dexmedetomidine as a sedative and analgesic agent in critically ill adult patients: a meta-analysis. Intensive Care Med 36(6):926-39

19. Mo Y, Zimmermann AE (2013) Role of dexmedetomidine for the prevention and treatment of delirium in intensive care unit patients. Ann Pharmacother 47(6):869-76

20. Bergendahl HT et al (2004) Clonidine vs. midazolam as premedication in children undergoing adeno-tonsillectomy: a prospective, randomized, controlled clinical trial. Acta Anaesthesiol Scand 48(10): 1292-300

21. Hunseler $\mathrm{C}$, et al. Continuous infusion of clonidine in ventilated newborns and infants: a randomized controlled trial. Pediatr Crit Care Med. 2014.

22. Jamadarkhana S, Gopal S (2010) Clonidine in adults as a sedative agent in the intensive care unit. J Anaesthesiol Clin Pharmacol 26(4):439-45

23. Pichot C, Ghignone M, Quintin L (2012) Dexmedetomidine and clonidine: from second- to first-line sedative agents in the critical care setting? J Intensive Care Med 27(4):219-37

24. Reyes JC et al (2012) The emerging of xylazine as a new drug of abuse and its health consequences among drug users in Puerto Rico. J Urban Health 89(3):519-26

25. Ruiz-Colon $\mathrm{K}$ et al (2014) Xylazine intoxication in humans and its importance as an emerging adulterant in abused drugs: a comprehensive review of the literature. Forensic Sci Int 240:1-8

26. Perry EC (2014) Inpatient management of acute alcohol withdrawal syndrome. CNS Drugs 28(5):401-10

27. Ungur LA et al (2013) Prevention and therapy of alcohol withdrawal on intensive care units: systematic review of controlled trials. Alcohol Clin Exp Res 37(4):675-86

28. Muncie HL Jr, Yasinian Y, Oge L (2013) Outpatient management of alcohol withdrawal syndrome. Am Fam Physician 88(9):589-95

29. Reid MC, Fiellin DA, O'Connor PG (1999) Hazardous and harmful alcohol consumption in primary care. Arch Intern Med 159(15): $1681-9$

30. Spies CD, Rommelspacher H (1999) Alcohol withdrawal in the surgical patient: prevention and treatment. Anesth Analg 88(4):946-54

31. Kosten TR, O'Connor PG (2003) Management of drug and alcohol withdrawal. N Engl J Med 348(18):1786-95

32. Fitzgerald PJ (2013) Elevated norepinephrine may be a unifying etiological factor in the abuse of a broad range of substances: alcohol, nicotine, marijuana, heroin, cocaine, and caffeine. Subst Abuse 7:171-83

33. Awissi DK et al (2013) Alcohol withdrawal and delirium tremens in the critically ill: a systematic review and commentary. Intensive Care Med 39(1):16-30

34. Awissi DK et al (2013) Alcohol, nicotine, and iatrogenic withdrawals in the ICU. Crit Care Med 41(9):S57-68

35. Mondavio M, Ghiazza GF (1989) [Use of clonidine in the prevention of alcohol withdrawal syndrome]. Minerva Med 80(11):1233-5

36. Mertes $\mathrm{N}$ et al (1996) Postoperative alpha 2-adrenergic stimulation attenuates protein catabolism. Anesth Analg 82(2):258-63

37. Spies CD et al (1995) Prophylaxis of alcohol withdrawal syndrome in alcohol-dependent patients admitted to the intensive care unit after tumour resection. Br J Anaesth 75(6):734-9

38. Ip Yam PC, Forbes A, Kox WJ (1992) Clonidine in the treatment of alcohol withdrawal in the intensive care unit. Br J Anaesth 68(1): $106-8$
39. Wilkins AJ, Jenkins WJ, Steiner JA (1983) Efficacy of clonidine in treatment of alcohol withdrawal state. Psychopharmacology (Berl) 81(1):78-80

40. Adinoff B (1994) Double-blind study of alprazolam, diazepam, clonidine, and placebo in the alcohol withdrawal syndrome: preliminary findings. Alcohol Clin Exp Res 18(4):873-8

41. Baumgartner GR, Rowen RC (1987) Clonidine vs chlordiazepoxide in the management of acute alcohol withdrawal syndrome. Arch Intern Med 147(7):1223-6

42. Baumgartner GR, Rowen RC (1991) Transdermal clonidine versus chlordiazepoxide in alcohol withdrawal: a randomized, controlled clinical trial. South Med J 84(3):312-21

43. Manhem $P$ et al (1985) Alcohol withdrawal: effects of clonidine treatment on sympathetic activity, the renin-aldosterone system, and clinical symptoms. Alcohol Clin Exp Res 9(3):238-43

44. Baumgartner GR (1988) Clonidine versus chlordiazepoxide in acute alcohol withdrawal: a preliminary report. South Med J 81(1):56-60

45. Bjorkqvist SE (1975) Clonidine in alcohol withdrawal. Acta Psychiatr Scand 52(4):256-63

46. Spies CD et al (1996) Therapy of alcohol withdrawal syndrome in intensive care unit patients following trauma: results of a prospective, randomized trial. Crit Care Med 24(3):414-22

47. Lansford CD et al (2008) Improved outcomes in patients with head and neck cancer using a standardized care protocol for postoperative alcohol withdrawal. Arch Otolaryngol Head Neck Surg 134(8): 865-72

48. Lenzenhuber E et al (1999) Gamma-hydroxybutyrate for treatment of alcohol withdrawal syndrome in intensive care patients. A comparison between with two symptom-oriented therapeutic concepts. Anaesthesist 48(2):89-96

49. Spies CD et al (2003) Alcohol withdrawal severity is decreased by symptom-orientated adjusted bolus therapy in the ICU. Intensive Care Med 29(12):2230-8

50. Riihioja P et al (1997) Dexmedetomidine alleviates ethanol withdrawal symptoms in the rat. Alcohol 14(6):537-44

51. Muzyk AJ et al (2013) Dexmedetomidine for the treatment of alcohol withdrawal syndrome: rationale and current status of research. CNS Drugs 27(11):913-20

52. DeMuro JP et al (2012) Use of dexmedetomidine for the treatment of alcohol withdrawal syndrome in critically ill patients: a retrospective case series. J Anesth 26(4):601-5

53. Frazee EN et al (2014) Influence of dexmedetomidine therapy on the management of severe alcohol withdrawal syndrome in critically ill patients. J Crit Care 29(2):298-302

54. Tolonen $J$ et al (2013) Dexmedetomidine in addition to benzodiazepine-based sedation in patients with alcohol withdrawal delirium. Eur J Emerg Med 20(6):425-7

55. Rayner SG et al (2012) Dexmedetomidine as adjunct treatment for severe alcohol withdrawal in the ICU. Ann Intensive Care 2(1):12

56. Mazanikov M et al (2013) Dexmedetomidine impairs success of patient-controlled sedation in alcoholics during ERCP: a randomized, double-blind, placebo-controlled study. Surg Endosc 27(6):2163-8

57. Mueller SW et al (2014) A randomized, double-blind, placebocontrolled dose range study of dexmedetomidine as adjunctive therapy for alcohol withdrawal. Crit Care Med 42(5):1131-9

58. Savel RH, Kupfer Y (2014) Using dexmedetomidine as adjunctive therapy for patients with severe alcohol withdrawal syndrome: another piece of the puzzle. Crit Care Med 42(5):1298-9

59. Bou Khalil R (2011) Tizanidine for alcohol withdrawal treatment. Med Hypotheses 77(4):548-9

60. Brunning J, Mumford JP, Keaney FP (1986) Lofexidine in alcohol withdrawal states. Alcohol Alcohol 21(2):167-70

61. Cushman P Jr et al (1985) Alcohol withdrawal syndromes: clinical management with lofexidine. Alcohol Clin Exp Res 9(2):103-8

62. Keaney $F$ et al (2001) A double-blind randomized placebocontrolled trial of lofexidine in alcohol withdrawal: lofexidine is 
not a useful adjunct to chlordiazepoxide. Alcohol Alcohol 36(5): 426-30

63. Muzyk AJ et al (2011) Role of alpha2-agonists in the treatment of acute alcohol withdrawal. Ann Pharmacother 45(5):649-57

64. Rehni AK, Jaggi AS, Singh N (2013) Opioid withdrawal syndrome: emerging concepts and novel therapeutic targets. CNS Neurol Disord Drug Targets 12(1):112-25

65. Krantz MJ, Mehler PS (2004) Treating opioid dependence. Growing implications for primary care. Arch Intern Med 164(3):277-88

66. Gold MS, Redmond DE Jr, Kleber HD (1978) Clonidine blocks acute opiate-withdrawal symptoms. Lancet 2(8090):599-602

67. Mannelli P et al (2012) The combination very low-dose naltrexoneclonidine in the management of opioid withdrawal. Am J Drug Alcohol Abuse 38(3):200-5

68. Monterubbianesi MC et al (2012) High opioid dosage rapid detoxification of cancer patient in palliative care with the Raffaeli model. J Opioid Manag 8(5):292-8

69. O'Mara K, Gal P, Davanzo C (2010) Treatment of neonatal withdrawal with clonidine after long-term, high-dose maternal use of tramadol. Ann Pharmacother 44(7-8):1342-4

70. Deutsch ES, Nadkarni VM (1996) Clonidine prophylaxis for narcotic and sedative withdrawal syndrome following laryngotracheal reconstruction. Arch Otolaryngol Head Neck Surg 122(11):1234-8

71. Malhotra A et al (1997) Clonidine versus withdrawal using an opioid in in-patient opioid detoxification. Eur Addict Res 3(3):146-149

72. Ziaaddini H, Nasirian M, Nakhaee N (2012) Comparison of the efficacy of buprenorphine and clonidine in detoxification of opioiddependents. Addict Health 4(3-4):79-86

73. Hartmann F et al (1991) Comparison of acetorphan with clonidine for opiate withdrawal symptoms. Am J Psychiatry 148(5):627-9

74. Akhondzadeh S et al (2000) Double-blind randomized controlled trial of baclofen vs. clonidine in the treatment of opiates withdrawal. J Clin Pharm Ther 25(5):347-53

75. Gossop M (1988) Clonidine and the treatment of the opiate withdrawal syndrome. Drug Alcohol Depend 21(3):253-9

76. Strang J, Bearn J, Gossop M (1999) Lofexidine for opiate detoxification: review of recent randomised and open controlled trials. Am J Addict 8(4):337-48

77. Gish EC et al (2010) Lofexidine, an \{alpha\}2-receptor agonist for opioid detoxification. Ann Pharmacother 44(2):343-51

78. Washton AM, Resnick RB, Geyer G (1983) Opiate withdrawal using lofexidine, a clonidine analogue with fewer side effects. J Clin Psychiatry 44(9):335-7

79. Yu E et al (2008) A phase 3 placebo-controlled, double-blind, multisite trial of the alpha-2-adrenergic agonist, lofexidine, for opioid withdrawal. Drug Alcohol Depend 97(1-2):158-68

80. McCambridge $J$ et al (2007) In-patient detoxification procedures, treatment retention, and post-treatment opiate use: comparison of lofexidine + naloxone, lofexidine + placebo, and methadone. Drug Alcohol Depend 88(1):91-5

81. Howells $\mathrm{C}$ et al (2002) Prison based detoxification for opioid dependence: a randomised double blind controlled trial of lofexidine and methadone. Drug Alcohol Depend 67(2):169-76

82. Doosti F et al (2013) Traditional Chinese and Indian medicine in the treatment of opioid-dependence: a review. Avicenna J Phytomed 3(3):205-15

83. Liu TT et al (2009) A meta-analysis of Chinese herbal medicine in treatment of managed withdrawal from heroin. Cell Mol Neurobiol 29(1):17-25

84. Shi J et al (2008) A comparative clinical study of the effects of the traditional Chinese medicine Jinniu capsules and lofexidine on acute heroin withdrawal symptoms. Am J Drug Alcohol Abuse 34(6):792-800

85. Lin SK et al (1997) Double-blind randomised controlled trial of lofexidine versus clonidine in the treatment of heroin withdrawal. Drug Alcohol Depend 48(2):127-33
86. Carnwath T, Hardman J (1998) Randomised double-blind comparison of lofexidine and clonidine in the out-patient treatment of opiate withdrawal. Drug Alcohol Depend 50(3):251-4

87. Walsh SL, Strain EC, Bigelow GE (2003) Evaluation of the effects of lofexidine and clonidine on naloxone-precipitated withdrawal in opioid-dependent humans. Addiction 98(4):427-39

88. San L et al (1990) Efficacy of clonidine, guanfacine and methadone in the rapid detoxification of heroin addicts: a controlled clinical trial. Br J Addict 85(1):141-7

89. Muga $\mathrm{R}$ et al (1990) Comparative effectiveness of alpha-2 adrenergic agonists (clonidine-guanfacine) in the hospital detoxification of opiate addicts. Med Clin (Barc) 94(5):169-72

90. Pinelli A, Trivulzio S, Spezia R (1998) Effects of tizanidine administration on precipitated opioid withdrawal signs in rats. Drug Alcohol Depend 50(1):81-8

91. Koyuncuoglu H et al (1992) Effects of tizanidine on morphine physical dependence: attenuation and intensification. Pharmacol Biochem Behav 42(4):693-8

92. Sos I et al (2000) [Tizanidine in the treatment of acute withdrawal symptoms in heroin dependent patients]. Orv Hetil 141(15):783-6

93. Koyuncuoglu H (1995) The combination of tizanidine markedly improves the treatment with dextromethorphan of heroin addicted outpatients. Int J Clin Pharmacol Ther 33(1):13-9

94. Davies MF et al (2003) Dexmedetomidine fails to cause hyperalgesia after cessation of chronic administration. Anesth Analg 96(1):195-200, table of contents

95. Hayashi Y, Guo TZ, Maze M (1996) Hypnotic and analgesic effects of the alpha2-adrenergic agonist dexmedetomidine in morphinetolerant rats. Anesth Analg 83(3):606-10

96. Oschman A, McCabe T, Kuhn RJ (2011) Dexmedetomidine for opioid and benzodiazepine withdrawal in pediatric patients. Am J Health Syst Pharm 68(13):1233-8

97. Tobias JD (2008) Subcutaneous dexmedetomidine infusions to treat or prevent drug withdrawal in infants and children. J Opioid Manag 4(4):187-91

98. Tobias JD (2006) Dexmedetomidine to treat opioid withdrawal in infants following prolonged sedation in the pediatric ICU. J Opioid Manag 2(4):201-5

99. Finkel JC, Johnson YJ, Quezado ZM (2005) The use of dexmedetomidine to facilitate acute discontinuation of opioids after cardiac transplantation in children. Crit Care Med 33(9):2110-2

100. Tobias JD, Berkenbosch JW, Russo P (2003) Additional experience with dexmedetomidine in pediatric patients. South Med J 96(9):871-5

101. Vega L et al (2013) Prevention of opioid withdrawal syndrome after pediatric heart transplantation: usefulness of dexmedetomidine. Rev Esp Cardiol (Engl Ed) 66(7):593-5

102. Upadhyay SP et al (2011) Dexmedetomidine infusion to facilitate opioid detoxification and withdrawal in a patient with chronic opioid abuse. Indian J Palliat Care 17(3):251-4

103. Multz AS (2003) Prolonged dexmedetomidine infusion as an adjunct in treating sedation-induced withdrawal. Anesth Analg 96(4): 1054-5, table of contents

104. Nasr DA et al (2011) Ultra-rapid opiate detoxification using dexmedetomidine under general anesthesia. J Opioid Manag 7(5): 337-44

105. Belgrade M, Hall S (2010) Dexmedetomidine infusion for the management of opioid-induced hyperalgesia. Pain Med 11(12): 1819-26

106. Gowing L et al (2014) Alpha2-adrenergic agonists for the management of opioid withdrawal. Cochrane Database Syst Rev 3: $\mathrm{Cd} 002024$

107. Gowing LR et al (2002) Alpha2-adrenergic agonists in opioid withdrawal. Addiction 97(1):49-58

108. Honey BL et al (2009) Alpha2-receptor agonists for treatment and prevention of iatrogenic opioid abstinence syndrome in critically ill patients. Ann Pharmacother 43(9):1506-11 
109. Benowitz NL (2010) Nicotine addiction. N Engl J Med 362(24): 2295-303

110. Markou A (2008) Review. Neurobiology of nicotine dependence. Philos Trans R Soc Lond B Biol Sci 363(1507):3159-68

111. D'Souza MS, Markou A (2011) Neuronal mechanisms underlying development of nicotine dependence: implications for novel smoking-cessation treatments. Addict Sci Clin Pract 6(1):4-16

112. D'Souza MS Markou A. The "stop" and "go" of nicotine dependence: role of GABA and glutamate. Cold Spring Harb Perspect Med. 2013. 3 (6).

113. Yamada H, Bruijnzeel AW (2011) Stimulation of alpha2-adrenergic receptors in the central nucleus of the amygdala attenuates stressinduced reinstatement of nicotine seeking in rats. Neuropharmacology 60(2-3):303-11

114. Lucidarme $\mathrm{O}$ et al (2010) Nicotine withdrawal and agitation in ventilated critically ill patients. Crit Care 14(2):R58

115. Hughes JR (2007) Effects of abstinence from tobacco: valid symptoms and time course. Nicotine Tob Res 9(3):315-27

116. Glassman AH et al (1984) Cigarette craving, smoking withdrawal, and clonidine. Science 226(4676):864-6

117. Gourlay S et al (1994) A placebo-controlled study of three clonidine doses for smoking cessation. Clin Pharmacol Ther 55(1):64-9

118. Glassman AH et al (1993) Smoking cessation, clonidine, and vulnerability to nicotine among dependent smokers. Clin Pharmacol Ther 54(6):670-9

119. Hao W, Young D (1988) Effect of clonidine on cigarette cessation and in the alleviation of withdrawal symptoms. Br J Addict 83(10):1221-6

120. Franks P, Harp J, Bell B (1989) Randomized, controlled trial of clonidine for smoking cessation in a primary care setting. Jama 262(21):3011-3

121. Ornish SA, Zisook S, McAdams LA (1988) Effects of transdermal clonidine treatment on withdrawal symptoms associated with smoking cessation. A randomized, controlled trial. Arch Intern Med 148(9):2027-31

122. Prochazka AV et al (1992) Transdermal clonidine reduced some withdrawal symptoms but did not increase smoking cessation. Arch Intern Med 152(10):2065-9

123. Cervantes Escarcega JL, Guadalajara Boo JF (1992) Effect of transdermal therapy with clonidine on suppression symptoms secondary to smoking cessation. Arch Inst Cardiol Mex 62(5):435-40

124. Hilleman DE et al (1989) Double-blind, placebo-controlled, evaluation of transdermal clonidine in smoking cessation. Chest 96(1):2085

125. Niaura RBR, Goldstein MG, Murphy JK, Abrams DB (1996) Transdermal clonidine for smoking cessation: a double-blind randomized dose-response study. Exp Clin Psychopharmacol 4(3):285-291

126. Hilleman DE et al (1993) Randomized, controlled trial of transdermal clonidine for smoking cessation. Ann Pharmacother 27(9): $1025-8$
127. Sees KL, Stalcup SA (1989) Combining clonidine and nicotine replacement for treatment of nicotine withdrawal. J Psychoactive Drugs 21(3):355-9

128. Cahill $\mathrm{K}$ et al (2013) Pharmacological interventions for smoking cessation: an overview and network meta-analysis. Cochrane Database Syst Rev 5:Cd009329

129. Gourlay SG, Stead LF, Benowitz NL. Clonidine for smoking cessation. Cochrane Database Syst Rev, 2004 (3): p. Cd000058.

130. Hansson L et al (1973) Blood pressure crisis following withdrawal of clonidine (Catapres, Catapresan), with special reference to arterial and urinary catecholamine levels, and suggestions for acute management. Am Heart J 85(5):605-10

131. Whalen LD, et al. Long-term dexmedetomidine use and safety profile among critically ill children and neonates. Pediatr Crit Care Med, 2014.

132. Kukoyi A et al (2013) Two cases of acute dexmedetomidine withdrawal syndrome following prolonged infusion in the intensive care unit: report of cases and review of the literature. Hum Exp Toxicol 32(1): $107-10$

133. FDA Med Watch. [cited 2014 8/30]; Available from: http://www. fda.gov/Safety/Med watch/Safety Information/ucm233675.htm.

134. Cushman P Jr (1987) Clonidine and alcohol withdrawal. Adv Alcohol Subst Abuse 7(1):17-28

135. Gold MS et al (1980) Opiate withdrawal using clonidine. A safe, effective, and rapid nonopiate treatment. Jama 243(4):343-6

136. Charney DS et al (1981) The clinical use of clonidine in abrupt withdrawal from methadone. Effects on blood pressure and specific signs and symptoms. Arch Gen Psychiatry 38(11):1273-7

137. Jasinski DR, Johnson RE, Kocher TR (1985) Clonidine in morphine withdrawal. Differential effects on signs and symptoms. Arch Gen Psychiatry 42(11):1063-6

138. Bearn J, Gossop M, Strang J (1996) Randomised double-blind comparison of lofexidine and methadone in the in-patient treatment of opiate withdrawal. Drug Alcohol Depend 43(1-2):87-91

139. Kahn A et al (1997) Double-blind study of lofexidine and clonidine in the detoxification of opiate addicts in hospital. Drug Alcohol Depend 44(1):57-61

140. Bearn J, Gossop M, Strang J (1998) Accelerated lofexidine treatment regimen compared with conventional lofexidine and methadone treatment for in-patient opiate detoxification. Drug Alcohol Depend 50(3):227-32

141. Bearn J et al (2001) The impact of naloxone/lofexidine combination treatment on the opiate withdrawal syndrome. Addict Biol 6(2): $147-156$

142. Beswick T et al (2003) The effectiveness of combined naloxone/ lofexidine in opiate detoxification: results from a double-blind randomized and placebo-controlled trial. Am J Addict 12(4):295305 